\title{
Gastric Hyperplastic Polyps: A Benign Entity? Analysis of Recurrence and Neoplastic Transformation in a Cohort Study
}

\author{
Mafalda João Miguel Areia Susana Alves Luís Elvas Filipe Taveira \\ Daniel Brito Sandra Saraiva Ana Teresa Cadime \\ Department of Gastroenterology, Portuguese Oncology Institute of Coimbra, Coimbra, Portugal
}

\section{Keywords}

Stomach neoplasms - Epidemiology · Pathology ·

Endoscopy · Digestive system

\section{Abstract}

Introduction: Hyperplastic polyps represent $30-93 \%$ of all gastric epithelial polyps. They are generally detected as innocuous incidental findings; however, they have a risk of neoplastic transformation and recurrence. Frequency and risk factors for neoplastic transformation and recurrence are not well established and are fields of ongoing interest. This study aims to evaluate the frequency of and identify the risk factors for recurrence and neoplastic change of gastric hyperplastic polyps (GHP). Methods: A single-centre retrospective cohort study including consecutive patients who underwent endoscopic resection of GHP from January 2009 to June 2020. Demographic, endoscopic, and histopathologic data was retrieved from the electronic medical records. $\boldsymbol{R e}$ sults: A total of 195 patients were included (56\% women; median age 67 [35-87] years). The median size of GHP was $10(3-50) \mathrm{mm}, 62 \%(n=120)$ were sessile, $61 \%(n=119)$ were located in the antrum, and $36 \%(n=71)$ had synchronous lesions. Recurrence rate after endoscopic resection was $23 \%$ $(n=26)$. In multivariate analysis, antrum location was the only risk factor for recurrence (odds ratio [OR] 3.0; 95\% con- fidence interval $[\mathrm{Cl}]$ 1.1-8.1). Overall, 5.1\% $(n=10)$ GHP showed neoplastic transformation, with low-grade dysplasia in 5, high-grade dysplasia in 4, and adenocarcinoma in 1. In multivariate analysis, a size $>25 \mathrm{~mm}$ (OR 84; 95\% Cl 7.4-954) and the presence of intestinal metaplasia (OR 7.6; $95 \% \mathrm{Cl}$ 1.0-55) and dysplasia (OR 86; 95\% Cl 10-741) in adjacent mucosa were associated with an increased risk of neoplastic transformation. Recurrence was not associated with neoplastic transformation (OR 1.1; 95\% Cl 0.2-5.9). Discussion: Our results confirmed the risk of recurrence and neoplastic transformation of GHP. Antrum location was a predictor of recurrence. The risk of neoplastic change was increased in large lesions and with intestinal metaplasia and dysplasia in adjacent mucosa. More frequent endoscopic surveillance may be required in these subgroups of GHP.

\footnotetext{
(c) 2021 Sociedade Portuguesa de Gastrenterologia Published by S. Karger AG, Basel
}

\section{Pólipos gástricos hiperplásicos: uma entidade benigna? Análise da recorrência e malignização num estudo de coorte}

Palavras Chave

Neoplasias gástricas - Epidemiologia · Patologia ·

Endoscopia $\cdot$ Sistema digestivo karger@karger.com www.karger.com/pjg

Karger $\stackrel{\text { ' }}{5}$

BOPEN ACCESS (c) 2021 Sociedade Portuguesa de Gastrenterologia Published by S. Karger AG, Basel

This is an Open Access article licensed under the Creative Commons Attribution-NonCommercial-4.0 International License (CC BY-NC) (http://www.karger.com/Services/OpenAccessLicense), applicable to the online version of the article only. Usage and distribution for commercial purposes requires written permission.
Correspondence to:

Mafalda João,mafaldacaine@gmail.com 


\section{Resumo}

Introdução e objetivos: Os pólipos hiperplásicos constituem 30-93\% das lesões gástricas epiteliais benignas. Apresentam-se frequentemente como achados endoscópicos incidentais inócuos, no entanto, apresentam risco de recorrência e transformação neoplásica. A frequência e fatores associados à recorrência e transformação neoplásica não estão bem estabelecidos e são áreas de interesse crescente. Este estudo pretende avaliar a frequência e identificar fatores associados à recorrência e transformação maligna dos pólipos gástricos hiperplásicos (PGH). Métodos: Estudo de coorte retrospectivo unicêntrico incluindo consecutivamente doentes com PGH submetidos a resseção endoscópica entre janeiro de 2009 e junho de 2020. Efetuada análise das características demográficas, endoscópicas e anatomopatológicas através dos registos clínicos eletrónicos. Sumários dos resultados: Incluídos 195 doentes género feminino: 56\%, idade mediana: 67 (35-87) anos. Os pólipos apresentavam tamanho mediano de $10(3-50) \mathrm{mm}, 61.5 \%(n=120)$ eram sésseis, 61\% ( $n=$ 119) apresentavam localização antral e $36 \%(n=71)$ tinham lesões síncronas. A frequência de recorrência foi $23 \%$ $(n=26)$. Na análise multivariada, apenas a localização no antro se associou significativamente a recorrência odds ratio (OR): 3.0; intervalo de confiança (IC) 95\%: 1.1-8.1). Em $5.1 \%(n=10)$ dos casos verificou-se transformação neoplásica, correspondendo a 5 casos de displasia de baixo grau, 4 casos de displasia de alto grau e 1 caso de carcinoma. Na análise multivariada, dimensão superior a $25 \mathrm{~mm}$ (OR: 84; IC95\%: 7.4-954), presença de metaplasia (OR: 7.6; IC95\%: 1.0-55) e displasia (OR: 86; IC95\%: 10-741) na mucosa adjacente associaram-se a transformação neoplásica. A recorrência não se associou a transformação neoplásica (OR: 1.1; IC95\%: 0.2-5.9). Discussão/Conclusão: Estes resultados corroboraram os riscos de recorrência e transformação neoplásica associados aos PGH. A localização antral foi preditor de recorrência. O risco de transformação neoplásica foi superior em lesões maiores e coexistência de metaplasia e displasia na mucosa adjacente. Poderá justificar-se uma estratégia de vigilância mais frequente nestes subgrupos.

( 2020 Sociedade Portuguesa de Gastrenterologia Publicado por S. Karger AG, Basel

\section{Introduction}

Hyperplastic polyps represent $30-93 \%$ of all gastric epithelial polyps $[1,2]$. They are characterized by hyperplastic foveola with an inflamed stroma, generally arising in response to a chronic inflammatory environment.
Their pathogenesis is unclear. The accepted hypothesis states that gastric hyperplastic polyps (GHP) develop as the result of a hyperplastic mucosal healing regenerative response secondary to an inflammatory process [3]. They are generally detected as innocuous incidental findings in $1.2-8 \%$ of patients undergoing esophago-gastro-duodenoscopy (EGD). However, they can be present as anaemia due to occult bleeding or gastric outlet obstruction $[1,4]$. Several risk factors for GHP have been identified, such as Helicobacter pylori infection [5], chronic atrophic gastritis [6], portal hypertension [5, 7], autoimmune gastritis [8], gastric surgery [9], and Ménétrier disease. Hypergastrinemia, induced by hypochlorhydria caused by chronic atrophic gastritis, has also been implicated in the pathogenesis of GHP [3]. EGD with white light shows sessile or pedunculated reddish lesions, generally $<20 \mathrm{~mm}$ in diameter and usually occurring as single lesions in the antrum (Fig. 1a). Narrow-band imaging typically shows a large regular mucosal pattern (Fig. 1b) [2]. Upon magnification of narrow-band imaging, GHP present a uniformly long, narrow, and elliptical marginal crypt epithelium with an unclear microvascular pattern [10].

Their potential for neoplastic change has been demonstrated for lesions with a diameter $>10 \mathrm{~mm}$, with a prevalence of dysplasia (low- and high-grade) ranging from 1.5 to $4.4 \%$, and a prevalence of carcinoma between 1.1 and $2.1 \%$. Horiuchi et al. [11] reported that combining a polyp size $>20 \mathrm{~mm}$ and features of magnification endoscopy with narrow-band imaging demonstrating an abnormal microvascular pattern and size reduction of the fine mucosal structure has nearly $100 \%$ sensitivity and $58 \%$ specificity for a diagnosis of cancer or dysplasia. However, the mechanisms responsible for the neoplastic change remain unknown [8]. Forté et al. [12] reported local recurrence in more than half of GHP > $10 \mathrm{~mm}$ in size after endoscopic resection. Unlike gastric adenomas and early gastric cancer, en bloc complete resection with free lateral and deep margins does not prevent local recurrence. Risk factors for local recurrence are not well described.

Current guidelines recommend endoscopic resection of all GHP > 5-10 $\mathrm{mm}$ and biopsy of the remaining tissue. Surrounding gastric mucosa should also be biopsied according to the management of epithelial pre-cancerous conditions and lesions in the stomach (MAPS II) guideline [13]. Additionally, H. pylori infection should be assessed and treated if present. Endoscopic follow-up is required 1 year after biopsy or endoscopic resection. If no residual polyp is found on surveillance endoscopy, further follow-up is according to the MAPS II guideline for the findings in the surrounding mucosa $[1,2]$. 

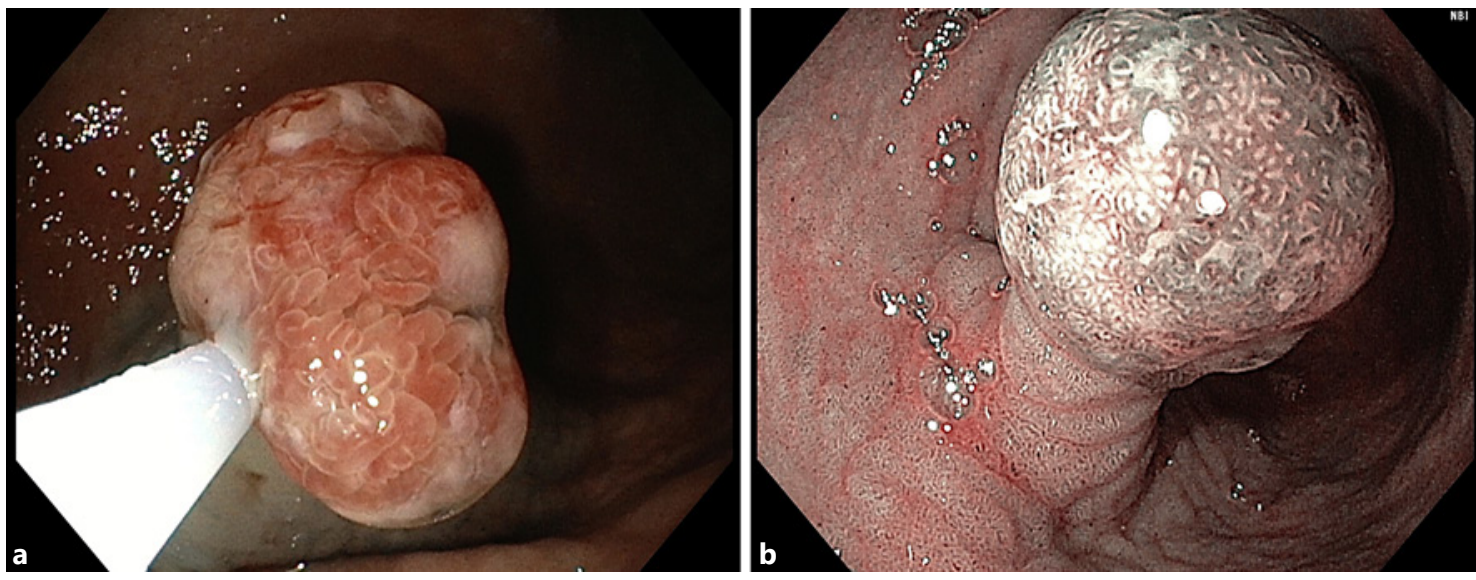

Fig. 1. Endoscopic typical appearance of gastric hyperplastic polyps (GHP). Esophagogastroduodenoscopy showing a typical reddish aspect on white-light imaging (a) and a large regular mucosal pattern on narrow-band imaging (b).

Recent knowledge concerning recurrence and neoplastic transformation rates as well as their predictors are in line with changes in current management of this type of polyp. The identification of high-risk factors for recurrence and neoplastic change will allow a better and selective management of these patients.

This study intended to characterize GHP population in a Western country and evaluate the proportion and risk factors for GHP recurrence and neoplastic transformation.

\section{Materials and Methods}

\section{Study Design}

This was a single-centre, retrospective, cohort study performed from January 2009 to June 2020.

\section{Inclusion and Exclusion Criteria}

Patients aged $\geq 18$ years who underwent endoscopic resection of GHP were consecutively included. Patients were excluded if the GHP was already a recurrence at the time of the first endoscopy, or if they underwent surgical resection of GHP, or had a hereditary gastric polyposis syndrome.

\section{Definitions}

The histological diagnosis of GHP was based on the following criteria: the presence of foveolar hyperplasia with long, deep, and hypersecreting crypts, or an inflammatory and abundant chorion. Neoplastic transformation was defined histologically by the presence of dysplasia or adenocarcinoma within GHP. Recurrence was defined by the presence of a histologically confirmed GHP at the previous complete resection of GHP at least 3 months after the initial resection.
Demographic, Clinical, Endoscopic, and Histologic Variables

Patients' characteristics, i.e., age, gender, proton-pump inhibitor intake, a history of gastric surgery, and the haemoglobin value were retrieved from electronic reports. Endoscopic data, i.e., GHP size, location, and morphology according to the Paris classification [14], endoscopic resection procedure, and adverse events were collected from EGD report. Histologic data, i.e., H. pylori infection, atrophic gastritis, intestinal metaplasia, neoplastic transformation and type, and complete resection with free lateral and deep margins were retrieved from the pathology report.

\section{Data and Statistical Analysis}

Continuous variables are reported as mean and SD or median and range if they had a normal or skewed distribution, respectively. Categorical variables are reported as absolute and relative frequencies. Continuous variables were compared between 2 groups using Student's $t$ test if they had normal distribution and homogeneity of variance, or the Mann-Whitney U test if these conditions were not met. Categorical variables were compared using Pearson's $\chi^{2}$ test or Fisher's exact test. To determine factors associated with recurrence and neoplastic transformation, univariate and multivariate analysis using a logistic regression model was performed. Covariates with a $p$ value $<0.05$ in the univariate analysis were included in the multivariate analysis. The effect of factors on the risk of recurrence and neoplastic transformation were quantified using odds ratio (OR) with $95 \%$ confidence interval (CI) in both analyses. Cumulative probabilities of recurrence were estimated by the Kaplan-Meier method. All hypotheses are 2 -tailed and a $p$ value $<0.05$ was considered statistically significant. Statistical analysis was performed using SPSS v25 (SPSS Inc., Chicago, IL, USA).

\section{Results}

In our study, from 364 epithelial gastric polyps submitted for endoscopic resection, 53.5\% $(n=195)$ were GHP. Of the 195 patients included, $56 \%(n=109)$ were female 
Fig. 2. Estimation of cumulative incidence of recurrence after first endoscopic resection of gastric hyperplastic polyps (GHP), 95\% CI.

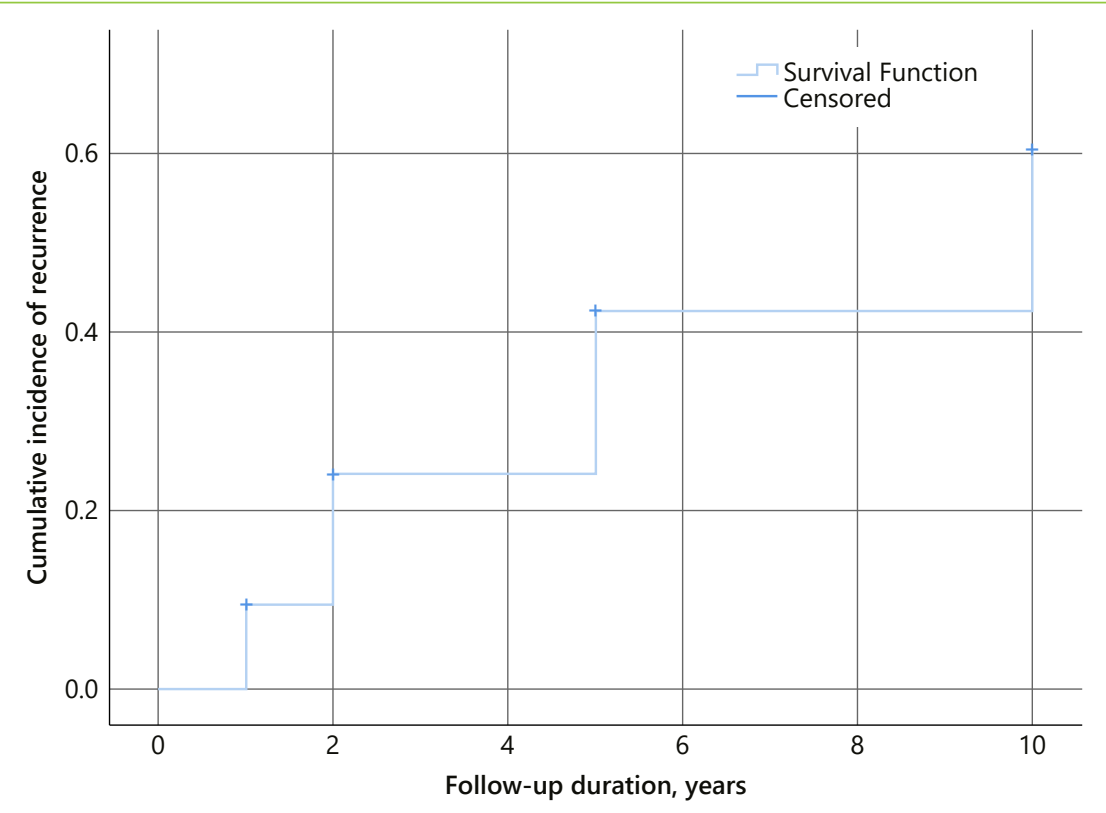

and the median age was 67 (35-87) years. The indications for performing the EGD were screening for early gastric cancer $(47 \%, n=91)$, anaemia $(24 \%, n=46)$, dyspepsia $(11 \%, n=21)$, and epigastric pain $(9 \%, n=18)$. The median size of GHP was $10(3-50) \mathrm{mm}$ and the majority were located in the antrum $(61 \%, n=119)$ and had a sessile morphology $(62 \%, n=120)$. Synchronous lesions, with inferior size, were present in $36 \%(n=71)$ of patients. Histologic findings of surrounding mucosa showed atrophic gastritis in $87 \%(n=169)$, intestinal metaplasia in $19 \%$ $(n=37)$, and dysplasia in $3.6 \%(n=7) . H$. pylori infection was detected in $29 \%(n=57)$ of the patients without any particular location; $41 \%$ were $H$. pylori-positive and $59 \%$ were $H$. pylori-negative $(p=0.8)$. Gastric surgery was described in 5.6\% $(n=11)$ patients. Proton-pump inhibitor intake was reported in $40 \%(n=78)$.

Hot-snare polypectomy was the technique for endoscopic resection performed in $38 \%(n=75)$ of the lesions, corresponding to pedunculated or sub-pedunculated lesions. Endoscopic mucosal resection was performed in the remaining $62 \%(n=120)$, corresponding to sessile lesions. No cold-snare polypectomies were performed. There were $16.7 \%(n=20)$ piecemeal resections. Postpolypectomy bleeding was recorded in $4 \%(n=8)$ of the cases, corresponding to 5 cases of intra-procedural bleeding managed with clips and/or snare-tip soft coagulation, and 3 cases of post-procedural bleeding. Neither perforation- nor sedation-related adverse events were reported (Table 1).

GHP: Analysis of Recurrence and Neoplastic Transformation
Table 1. Baseline demographic, clinical, and pathologic characteristics of 195 patients
Female gender

Median age, years (range)

EGD indication

Screening for early gastric cancer

Anaemia

Dyspepsia

Epigastric pain

Other

Median size, $\mathrm{mm}$ (range)

Paris classification

0 -Is

0 -Isp

0 -Ip

Location

Antrum

Corpus

Cardia/fundus

$H$. pylori infection

Atrophic gastritis

Intestinal metaplasia

Dysplasia

Synchronous lesions

Medication

Proton-pump inhibitors

Antithrombotic agents

Gastric surgery

Recurrence

Neoplastic transformation
$109(56)$

$67(35-87)$

91 (47)

46 (24)

$21(11)$

18 (9)

$19(9)$

$10(3-50)$

$120(62)$

18 (9)

57 (29)

$119(61)$

$54(28)$

22 (11)

$57(29)$

$169(88)$

37 (19)

$7(3.6)$

$71(36)$

$78(40)$

$48(25)$

$11(5.6)$

$26(13)$

$10(5.1)$
Values are expressed as $n(\%)$, unless otherwise indicated. EGD, esophago-gastro-duodenoscopy; 0-Is, sessile; 0-Isp, sub-pedunculated; 0-Ip, pedunculated. 
Table 2. Main results and analysis of risk factors associated with recurrence

\begin{tabular}{|c|c|c|c|c|c|}
\hline \multirow[t]{2}{*}{ Risk factors } & \multirow{2}{*}{$\begin{array}{l}\text { With } \\
\text { recurrence } \\
(n=26), \%\end{array}$} & \multirow{2}{*}{$\begin{array}{l}\text { Without } \\
\text { recurrence } \\
(n=87), \%\end{array}$} & \multicolumn{3}{|c|}{ Univariate analysis } \\
\hline & & & OR & $95 \%$ CI & $p$ value \\
\hline Age $>65$ years & 58 & 58 & 1.0 & $0.4-2.4$ & 0.98 \\
\hline Male gender & 54 & 39 & 0.6 & $0.2-1.3$ & 0.18 \\
\hline Gastric surgery & 3.8 & 9.2 & 0.4 & $0.1-3.3$ & 0.39 \\
\hline Anaemia & 69 & 29 & 1.1 & $0.4-2.8$ & 0.89 \\
\hline Proton-pump inhibitor intake & 54 & 39 & 1.8 & $0.7-4.6$ & 0.20 \\
\hline Polyp size $25 \mathrm{~mm}$ & 3.8 & 3.4 & 1.1 & $0.1-11$ & 0.92 \\
\hline \multicolumn{6}{|l|}{ Polyp location } \\
\hline Antrum & 77 & 53 & 3.0 & $1.1-8.1$ & 0.03 \\
\hline Corpus & 23 & 4 & & & \\
\hline Pedunculated morphology & 27 & 26 & 1.03 & $0.4-2.8$ & 0.96 \\
\hline Synchronous lesions & 42 & 43 & 1.0 & $0.4-2.4$ & 0.98 \\
\hline H. pylori infection & 38 & 32 & 1.3 & $0.5-3.3$ & 0.55 \\
\hline \multicolumn{6}{|c|}{ Pre-neoplastic conditions and lesions } \\
\hline Atrophic gastritis & 92 & 77 & 3.6 & $0.8-16$ & 0.10 \\
\hline Intestinal metaplasia & 15 & 25 & 0.5 & $0.2-1.7$ & 0.30 \\
\hline Dysplasia & 0 & & 0 & 0 & 1 \\
\hline Neoplastic transformation & 8 & 7 & 1.1 & $0.2-5.9$ & 0.9 \\
\hline
\end{tabular}

Of the study population, $58 \%(n=113)$ patients had at least 1 EGD follow-up. The median time for the first EGD was $1(1-5)$ years, with $94 \%(n=106)$ performed at 1 year. After the initial resection, 23\% $(n=26)$ recurrences were identified, $69 \%(n=18)$ of which were detected at the first EGD follow-up. Median size of GHP with recurrence was $10(6-40) \mathrm{mm}, 80 \%(n=20)$ were in the antrum, and $43 \%$ $(n=11)$ had synchronic lesions. $H$. pylori infection was reported in 39\% $(n=10)$ cases. Regarding pre-malignant conditions, in patients with recurrence, atrophic gastritis was present in $92 \%(n=24)$ and intestinal metaplasia in $16 \%(n=4)$. Dysplasia was not reported. Anaemia was present in $69 \%(n=18)$ of the patients. Recurrence was significantly higher in polyps located in the antrum than in the corpus/fundus ( 80 vs. $53 \%$, OR 3.0; $95 \%$ CI 1.18.1). Gender, age, polyp size and morphology, $H$. pylori status, pre-malignant gastric conditions in the surrounding mucosa, and haemoglobin value were not associated with recurrence (Table 2). Of the 26 recurrent GHP, 15 were submitted for a new endoscopic resection. In the remaining patients, the biopsy confirmed hyperplastic origin and no further treatment or surveillance was performed. After the first re-treatment, 4 were lost to followup. A recurrence frequency of $36 \%$ (4/11) was reported after endoscopic resection of the first recurrence. The median time to recurrence was estimated at 7.5 (95\% CI 6.78.4) years (Fig. 2).
Neoplastic transformation was identified in 10 GHP, 5 with low-grade dysplasia, 4 with high-grade dysplasia, and 1 with an intra-mucosal carcinoma. Median size of GHP with neoplastic transformation was 17 (10-50) $\mathrm{mm}, 60 \%(n=6)$ of GHP were located in the antrum, and $60 \%(n=6)$ had synchronic lesions. H. pylori infection was reported in $40 \%(n=4)$. In these patients with a GHP with neoplastic transformation, pre-malignant conditions in adjacent mucosa were present in $100 \%$ $(n=10), 100 \%(n=10)$ had chronic gastritis, $60 \%(n=$ $6)$ had intestinal metaplasia, and $50 \%(n=5)$ had dysplasia (Table 3).

Univariate analysis found that a GHP size $>25 \mathrm{~mm}$, intestinal metaplasia, and/or dysplasia in surrounding mucosa were associated with neoplastic transformation. Neoplastic transformation was significantly higher in GHP with a diameter $>25 \mathrm{~mm}$ (80 vs. $20 \%$; OR 15 ; $95 \%$ CI 2.2-104), and with intestinal metaplasia (60 vs. $17 \%$; OR 7.5; 95\% CI 2.0-28), or dysplasia (50 vs. 1.0\%; OR 92; 95\% CI 14-591) in adjacent mucosa. Multivariate analysis after backward selection found that a size $>25 \mathrm{~mm}$ (OR 84; 95\% CI 7.4-954), intestinal metaplasia (OR 7.6; 95\% CI 1.0-55), and dysplasia (OR 86; 95\% CI 10-741) remained significantly associated with neoplastic transformation (Table 3). 
Table 3. Analysis of risk factors associated with neoplastic transformation

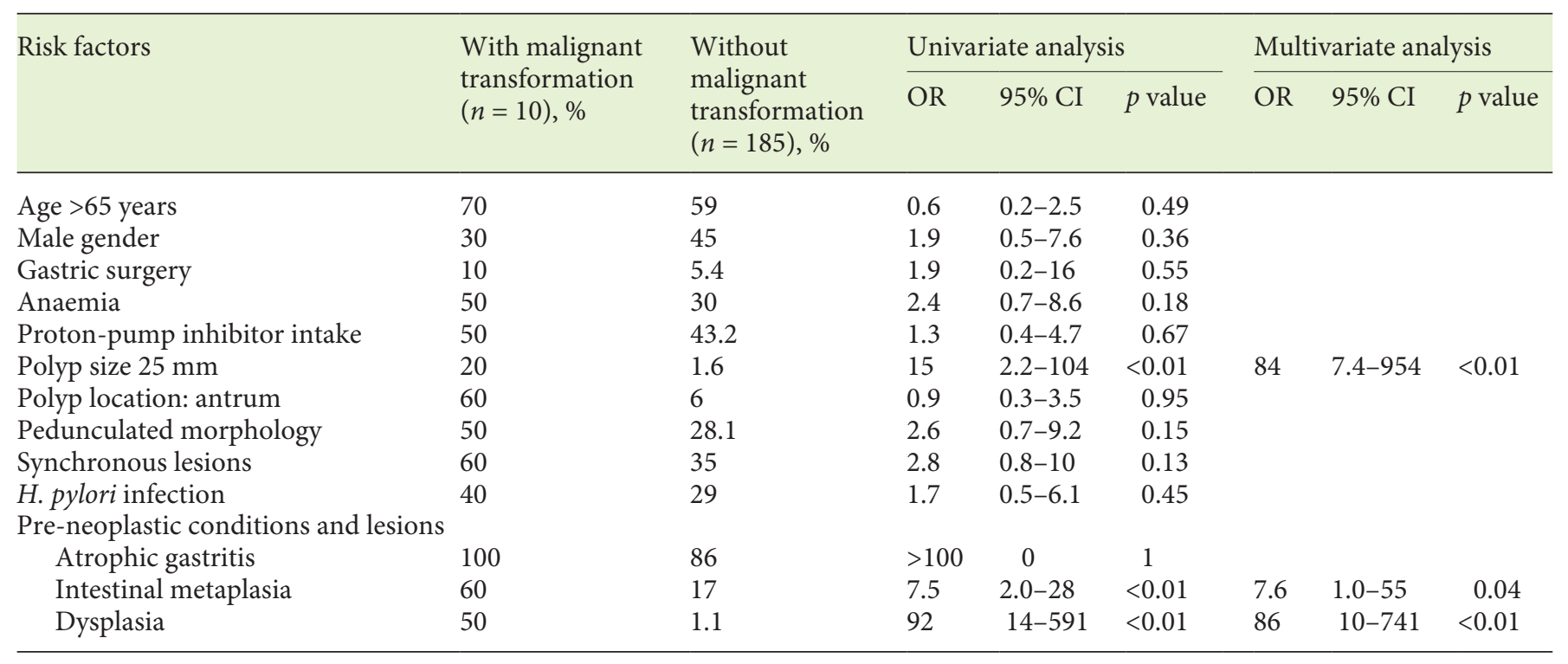

\section{Discussion}

In our population, the frequency of GHP was higher than reported in studies from the USA and from other European countries, but similar to that reported in a Brazilian study [15-17]. This data is in line with the high prevalence of $H$. pylori infection in Portugal compared with other Western countries [18]. As reported in previous studies, GHP were more frequent in females [15]. Endoscopic findings are in accordance with previous studies regarding median size, sessile morphology, and antrum location [1]. The proportion of $H$. pylori infection at the time of endoscopic resection (29\%) was comparable with previous data descriptions of percentages between 15 and $37 \%[12,19]$. However, this proportion was lower than expected, taking into account the prevalence of $H$. pylori infection in Portugal [18]; it can be explained by previous eradication and false-negatives introduced by protonpump inhibitor intake in a considerable percentage of the patients (40\%). Furthermore, Giemsa coloration of histopathologic specimens was the diagnostic test used for $H$. pylori detection. This method has a lower sensitivity (83\%) than immunohistochemistry and fluorescence in situ hybridization; this, together with the high frequency of atrophic gastritis (87\%), may have led to an underestimation of the real prevalence of $H$. pylori infection [20]. Concerning the advanced stages of gastritis, gastric atrophy was present in $87 \%$, intestinal metaplasia in $19 \%$, and dysplasia in $3.6 \%$ of our patients. Previous data also dem-

GHP: Analysis of Recurrence and

Neoplastic Transformation onstrated the higher prevalence of epithelial pre-cancerous conditions in patients with GHP $[3,8]$. In our study, the updated Sydney system was not used, defaulting further conclusions [21].

The study showed local recurrence in $23 \%$ of the patients. It revealed that GHP recurrence was more frequent for polyps located in the antrum, in agreement with a previous study conducted by Forté et al. [12]. One of the possible hypotheses for taking into account GHP location is that the mucosal trauma induced by contractions of the antrum or duodeno-gastric reflux could promote the hyperplastic wound-healing process $[12,22]$. The mechanism of recurrence remains unclear. However, it seems that it can be explained, at least in part, by the iteration of the wound-healing process. Recurrent lesions can be treated by endoscopic resection, as described in most cases, despite the presence of sub-mucosal fibrosis.

Similar to the findings of Forté et al. [12], in our cohort, GHP $>25 \mathrm{~mm}$ had a higher neoplastic potential as well as advanced gastritis stages such as intestinal metaplasia and dysplasia. Although intestinal metaplasia and atrophic gastritis have been reported as risk factors in some studies [3,19], others found no correlation between these factors and the occurrence of neoplasia [23]. A Japanese study suggested that GHP with neoplastic changes develop via a hyperplasia-dysplasia-carcinoma sequence rather than an intestinal metaplasia-dysplasia-carcinoma sequence [24]. Given the controversial data, whether therapy should be directed toward the underlying pathol- 
ogy rather than the polyp itself remains a relevant question under investigation [25]. Hypergastrinemia, not evaluated in our cohort, has also been implicated in neoplastic transformation, namely in the autoimmune gastritis setting [8].

In this study, recurrence was not a risk factor for neoplastic change. No previous study had demonstrated a positive association between recurrence and neoplastic change.

This study has some limitations. First, it was performed in a single tertiary centre and was designed retrospectively. Therefore, some data is missing, namely $H$. $p y$ lori eradication, the haemoglobin value, and current medication. Additionally, an adequate staging and grading of intestinal metaplasia and gastric atrophy, with biopsies of at least 2 topographic sites (from both the antrum and the corpus, at the lesser and greater curvature) taken and clearly labelled in to 2 separate vials [13], was performed only in $21 \%$ of patients. Although recurrence was defined as GHP developing at the resection scar, it is possible that some of the new GHP were mistakenly considered as recurrent lesions, owing to close proximity, a faded scar, or evaluation by a different endoscopist. Finally, endoscopic surveillance intervals were based on the clinician's decision and did not follow a uniform protocol. A uniform endoscopic follow-up protocol and a prospective cohort study seem warranted to confirm our conclusions and better define recurrence time, patterns, and management as well as risk factors for neoplastic transformation.

In conclusion, this study characterized population with GHP polyps in a Western country and evaluated the risk factors for recurrence and neoplastic transformation. Lesions $>25 \mathrm{~mm}$ with advanced stages of atrophic gastritis require endoscopic resection, and gastric mucosa needs endoscopic surveillance. However, in the absence of other high-risk features, particularly intestinal metaplasia and dysplasia in the surrounding mucosa, endo- scopic resection and follow-up of smaller lesions (10-25 $\mathrm{mm}$ ) should be more selectively performed. Recurrence, frequent in GHP, is not a predictor of neoplastic transformation. In summary, a tailored endoscopic approach for GHP could reduce costs and morbidity as well as optimize the use of human and material resources, in line with the recently published guidelines of the European Society of Gastrointestinal Endoscopy [26].

\section{Statement of Ethics}

The authors declare that no experiments were performed on humans or animals for this study, that they have followed the protocols of their work centre on the publication of patient data, and that no patient data appear in this article.

\section{Conflict of Interest Statement}

The authors have no conflicts of interest to declare.

Funding Sources

There was no funding.

\section{Author Contributions}

M.J.: conception and design of the study, acquisition, analysis, and interpretation of data, and drafting the manuscript. M.A.: conception and design of the study, analysis and interpretation of data, and critical revision the manuscript. S.A., D.B., L.E., F.T., and S.S.: execution of the procedures, acquisition of data, and critical revision the manuscript. A.T.C.: critical revision of the manuscript for important intellectual content. All authors approved the published version of the manuscript and agreed to be accountable for all aspects of the work ensuring questions related to the accuracy or integrity of any part of the work were appropriately evaluated and resolved.

\section{References}

1 Goddard AF, Badreldin R, Pritchard DM, Walker MM, Warren B; British Society of Gastroenterology. The management of gastric polyps. Gut. 2010 Sep;59(9):1270-6.

2 Castro R, Pimentel-Nunes P, Dinis-Ribeiro $M$. Evaluation and management of gastric epithelial polyps. Best Pract Res Clin Gastroenterol. 2017 Aug;31(4):381-7.

3 Jain R, Chetty R. Gastric hyperplastic polyps: a review. Dig Dis Sci. 2009 Sep;54(9):1839-46.
4 Gencosmanoglu R, Sen-Oran E, KurtkayaYapicier O, Tozun N. Antral hyperplastic polyp causing intermittent gastric outlet obstruction: case report. BMC Gastroenterol. 2003 Jun;3(1): 16

5 Elhanafi S, Saadi M, Lou W, Mallawaarachchi I, Dwivedi A, Zuckerman M, et al. Gastric polyps: association with Helicobacter pylori status and the pathology of the surrounding mucosa, a cross sectional study. World J Gastrointest Endosc. 2015 Aug;7(10):995-1002.
6 Han AR, Sung CO, Kim KM, Park CK, Min $\mathrm{BH}$, Lee JH, et al. The clinicopathological features of gastric hyperplastic polyps with neoplastic transformations: a suggestion of indication for endoscopic polypectomy. Gut Liver. 2009 Dec;3(4):271-5.

7 De Lisi S, Peralta S, Arini A, Simone F, Craxì A. Oesophagogastroduodenoscopy in patients with cirrhosis: extending the range of detection beyond portal hypertension. Dig Liver Dis. 2011 Jan;43(1):48-53. 
$8 \mathrm{Hu} \mathrm{H}$, Zhang Q, Chen G, Pritchard DM, Zhang S. Risk factors and clinical correlates of neoplastic transformation in gastric hyperplastic polyps in Chinese patients. Sci Rep. $2020 \mathrm{Feb} ; 10(1): 2582$.

9 Joffe N, Goldman H, Antonioli DA. Recurring hyperplastic gastric polyps following subtotal gastrectomy. AJR Am J Roentgenol. $1978 \mathrm{Feb} ; 130(2): 301-5$.

10 Hasegawa R, Yao K, Ihara S, Miyaoka M, Kanemitsu T, Chuman K, et al. Magnified Endoscopic Findings of Multiple White Flat Lesions: A New Subtype of Gastric Hyperplastic Polyps in the Stomach. Clin Endosc. 2018 Nov;51(6):558-62.

11 Horiuchi H, Kaise M, Inomata H, Yoshida Y, Kato $\mathrm{M}$, Toyoizumi $\mathrm{H}$, et al. Magnifying endoscopy combined with narrow band imaging may help to predict neoplasia coexisting with gastric hyperplastic polyps. Scand J Gastroenterol. 2013 May;48(5):626-32.

12 Forté E, Petit B, Walter T, Lépilliez V, Vanbiervliet G, Rostain F, et al. Risk of neoplastic change in large gastric hyperplastic polyps and recurrence after endoscopic resection. Endoscopy. 2020 Jun;52(6):444-53.

13 Pimentel-Nunes P, Libânio D, Marcos-Pinto R, Areia M, Leja M, Esposito G, et al. Management of epithelial precancerous conditions and lesions in the stomach (MAPS II): European Society of Gastrointestinal Endoscopy (ESGE), European Helicobacter and Microbiota Study Group (EHMSG), European Society of Pathology (ESP), and Sociedade Por- tuguesa de Endoscopia Digestiva (SPED) guideline update 2019. Endoscopy. 2019 Apr; 51(4):365-88

14 van Doorn SC, Hazewinkel Y, East JE, van Leerdam ME, Rastogi A, Pellisé M, et al. Polyp morphology: an interobserver evaluation for the Paris classification among international experts. Am J Gastroenterol. 2015 Jan;110(1): $180-7$.

15 Sonnenberg A, Genta RM. Prevalence of benign gastric polyps in a large pathology database. Dig Liver Dis. 2015 Feb;47(2):164-9.

16 Morais DJ, Yamanaka A, Zeitune JM, Andreollo NA. Gastric polyps: a retrospective analysis of 26,000 digestive endoscopies. Arq Gastroenterol. 2007 Jan-Mar;44(1):14-7.

17 Stolte M, Sticht T, Eidt S, Ebert D, Finkenzeller G. Frequency, location, and age and sex distribution of various types of gastric polyp. Endoscopy. 1994 Oct;26(8):659-65.

18 Venneman K, Huybrechts I, Gunter MJ, Vandendaele L, Herrero R, Van Herck K. The epidemiology of Helicobacter pylori infection in Europe and the impact of lifestyle on its natural evolution toward stomach cancer after infection: A systematic review. Helicobacter. 2018 Jun;23(3):e12483.

19 Dirschmid K, Platz-Baudin C, Stolte M. Why is the hyperplastic polyp a marker for the precancerous condition of the gastric mucosa? Virchows Arch. 2006 Jan;448(1):80-4.

20 Kocsmár É, Szirtes I, Kramer Z, Szijártó A, Bene L, Buzás GM, et al. Sensitivity of Helicobacter pylori detection by Giemsa staining is poor in comparison with immunohistochemistry and fluorescent in situ hybridization and strongly depends on inflammatory activity. Helicobacter. 2017 Aug;22(4):e12387.

21 Dixon MF, Genta RM, Yardley JH, Correa P. Classification and grading of gastritis. The updated Sydney System. International Workshop on the Histopathology of Gastritis, Houston 1994. Am J Surg Pathol. 1996 Oct; 20(10):1161-81.

22 Mikhaúlusov SV, Bart BI, Siluianov SV, Mikhaĭlusova MP, Nikolaeva AS. [Duodenogastric reflux and gastric pathology in the elderly patients]. Eksp Klin Gastroenterol. 2010;12(12):54-9.

23 Ahn JY, Son DH, Choi KD, Roh J, Lim H, Choi KS, et al. Neoplasms arising in large gastric hyperplastic polyps: endoscopic and pathologic features. Gastrointest Endosc. 2014 Dec;80(6):1005-13.e2.

24 Terada T. Malignant transformation of foveolar hyperplastic polyp of the stomach: a histopathological study. Med Oncol. 2011 Dec; 28(4):941-4.

25 Bapaye A. Large gastric hyperplastic polyps: to resect or not to resect, that is the question! Endoscopy. 2020 Jun;52(6):424-6.

26 Rodríguez-de-Santiago E, Frazzoni L, Fuccio L, van Hooft JE, Ponchon T, Hassan C, et al. Digestive findings that do not require endoscopic surveillance - Reducing the burden of care: European Society of Gastrointestinal Endoscopy (ESGE) Position Statement. Endoscopy. 2020 Jun;52(6):491-7. 